\title{
KRAS mutations in primary tumours and post-FOLFOX metastatic lesions in cases of colorectal cancer
}

\section{Y Kawamoto ${ }^{1,2,3,4}$, K Tsuchihara $^{*, 2}$, T Yoshino $^{3}$, N Ogasawara $^{2}$, M Kojima $^{5}$, M Takahashi $^{3}$, A Ochiai $^{5}$,

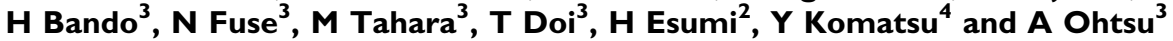

'Department of Gastroenterology, Hokkaido University Graduate School of Medicine, Sapporo 060-8638, Japan; ${ }^{2}$ Cancer Physiology Project, Research Center for Innovative Oncology, National Cancer Center Hospital East, Kashiwa 277-8577, Japan; ${ }^{3}$ Department of Gastroenterology and Gastrointestinal Oncology, National Cancer Center Hospital East, Kashiwa 277-8577, Japan; ${ }^{4}$ Department of Cancer Center, Hokkaido University Hospital, Sapporo 060-8638, Japan; ${ }^{5}$ Pathology Division, Research Center for Innovative Oncology, National Cancer Center Hospital East, Kashiwa $277-8577$ Japan

BACKGROUND: KRAS mutations are predictive markers for the efficacy of anti-EGFR antibody therapies in patients with metastatic colorectal cancer. Although the mutational status of KRAS is reportedly highly concordant between primary and metastatic lesions, it is not yet clear whether genotoxic chemotherapies might induce additional mutations.

METHODS: A total of 63 lesions (23 baseline primary, 18 metastatic and 24 post-treatment metastatic) from 21 patients who were treated with FOLFOX as adjuvant therapy for stage III/IV colorectal cancer following curative resection were examined. The DNA samples were obtained from formalin-fixed paraffin-embedded specimens, and KRAS, NRAS, BRAF and PIK3CA mutations were evaluated.

RESULTS: The numbers of primary lesions with wild-type and mutant KRAS codons 12 and 13 were 8 and 13, respectively. The mutational status of KRAS remained concordant between the primary tumours and the post-FOLFOX metastatic lesions, irrespective of patient background, treatment duration and disease-free survival. Furthermore, the mutational statuses of the other genes evaluated were also concordant between the primary and metastatic lesions.

CONCLUSION: Because the mutational statuses of predictive biomarker genes were not altered by FOLFOX therapy, specimens from both primary tumours and post-FOLFOX tumour metastases might serve as valid sources of DNA for known genomic biomarker testing.

British Journal of Cancer (2012) I 07, 340-344. doi:I0.1038/bjc.2012.218 www.bjcancer.com

Published online 22 May 2012

(C) 2012 Cancer Research UK

Keywords: colorectal cancer; genomic biomarker; KRAS; anti-EGFR antibody; oxaliplatin

KRAS mutations are predictive markers for the poor efficacy of anti-EGFR antibody therapies in patients with metastatic colorectal cancer (Lievre et al, 2006; Benvenuti et al, 2007; Di Fiore et al, 2007; Frattini et al, 2007; Khambata-Ford et al, 2007; Amado et al, 2008; De Roock et al, 2008; Freeman et al, 2008; Karapetis et al, 2008; Lievre et al, 2008). Point mutations in the KRAS gene occur early in the progression from colorectal adenoma to carcinoma and are detected in $35-40 \%$ of patients, regardless of their Dukes stage (Andreyev et al, 1998). More than $90 \%$ of the KRAS mutations in these patients have been detected in codons 12 (GGT) and 13 (GGC) (Oliveira et al, 2004). Activating mutations at codons 61 and 146 have also been reported in a small number of these tumours. In addition, mutations in the molecules involved in signalling pathways downstream of EGFR, such as NRAS, BRAF and PIK3CA, have also been reported in colorectal cancers. These mutations have been suggested to modify the efficacy of anti-EGFR

*Correspondence: Dr K Tsuchihara; E-mail: ktsuchih@east.ncc.go.jp Received 14 February 2012; revised 25 April 2012; accepted 29 April 2012; published online 22 May 2012 antibody therapies, although their predictive value has not yet been established (De Roock et al, 2010).

Oxaliplatin [trans-R,R-1,2-diaminocyclohexaneoxalatoplatinum (II), L-OHP] is a third-generation platinum (Pt)-containing antitumour compound. It is frequently administered as a component of FOLFOX therapy in combination with 5-FU for patients with metastatic colorectal cancer. Oxaliplatin induces DNA damage associated with intra- and inter-strand cross-links (Pt-GG adducts) and can induce gene mutations (Woynarowski et al, 2000; Hah et al, 2007; Sharma et al, 2007). The mutagenic activity of oxaliplatin has been demonstrated in cultured cells (Silva et al, 2005).

The KRAS mutation status of primary and metastatic lesions is reportedly highly concordant (Oudejans et al, 1991; Losi et al, 1992; Suchy et al, 1992; Zauber et al, 2003; Weber et al, 2007; Etienne-Grimaldi et al, 2008; Santini et al, 2008; Garm Spindler et al, 2009; Loupakis et al, 2009; Perrone et al, 2009; Baldus et al, 2010; Italiano et al, 2010; Knijn et al, 2011). However, whether long-term treatment with genotoxic chemotherapies, such as oxaliplatin, can induce additional mutations in metachronous metastatic lesions has not yet been well examined.

Assuming that FOLFOX therapy has the potential to alter the biomarker mutation profile, it is important to determine whether 
the primary or relapsed tumour represents the more appropriate source of DNA for testing. We examined the mutation status of $K R A S$ and other biomarker genes in primary and synchronous/ metachronous metastatic lesions in patients with stage III/IV colorectal cancer treated with adjuvant FOLFOX therapy following curative resection.

\section{PATIENTS AND METHODS}

\section{Patient selection}

A total of 63 lesions from 21 patients who had received adjuvant FOLFOX therapy for stage III/IV colorectal cancer following curative resection at the National Cancer Center Hospital East, Japan, between January 2006 and December 2009 were examined.

All patients were treated with a modified FOLFOX6 regimen, with a reduced oxaliplatin dose of $85 \mathrm{mg} \mathrm{m}^{-2}$ administered every 14 days, and 12 cycles were planned as the full therapy course (Andre et al, 2004; Allegra et al, 2009). FOLFOX therapy was discontinued when tumour relapse was demonstrated by imaging or when intolerable adverse events occurred.

\section{DNA samples and mutational analyses}

The DNA samples were obtained from macroscopically dissected formalin-fixed paraffin-embedded specimens cut into $10-\mu \mathrm{m}$-thick sections. Genomic DNA was extracted using the EZ1 Advanced XL and EZ1 DNA Tissue Kits (Qiagen, Hilden, Germany) according to the manufacturer's instructions (Bando et al, 2011). Mutations in KRAS codons 12 and 13 were detected using the ARMS/ Scorpions technology-based KRAS PCR Kit (Qiagen) according to the manufacturer's instructions. Mutations in KRAS codons 61 and 146, NRAS codons 12, 13 and 61, BRAF codon 600 and PIK3CA codons 542, 545, 546 and 1047 were detected using the multiplex PCR-Luminex method-based MEBGEN Mutation Kit (Medical \& Biological Laboratories, Nagoya, Japan). Mutations detected with the MEBGEN Mutation Kit were confirmed by direct sequencing. Mutations in PIK3CA codons 542, 545 and 546 were further confirmed using the ARMS/Scorpions technology-based PI3K Mutation Test Kit (Qiagen). The study was approved by the Institutional Review Board of the National Cancer Center.

\section{RESULTS}

\section{Patient and tumour site characteristics}

We reviewed 151 consecutive cases of stage III/IV colorectal cancer treated with an adjuvant FOLFOX therapy after curative resection. Among these cases, 21 patients developed metastatic tumours that were diagnosed during or after the FOLFOX therapy and surgically resected. The patient and tumour site characteristics are shown in Table 1 . The primary tumour sites were the colon and rectum in 8 and 13 patients, respectively. The most abundant primary tumour histopathological type was differentiated adenocarcinoma. Well- and moderately differentiated adenocarcinomas and mucinous adenocarcinomas were observed in 5, 14 and 2 patients, respectively. All metastatic tumours exhibited histology concordant with that of the associated primary colorectal adenocarcinoma.

In all, 12 patients had stage III disease, whereas the remaining 9 patients had synchronous metastatic lesions and were diagnosed as stage IV at the initial operation. There were 12 synchronous metastatic lesions in the patients with stage IV disease. In addition, six metastatic lesions were detected in five patients with stage III disease at operation that were resected prior to the start of FOLFOX therapy. These 18 lesions were regarded as 'pre-FOLFOX' metastatic lesions. The pre-FOLFOX metastases were found in the
Table I Characteristics

\begin{tabular}{lc}
\hline Patient characteristics & Number \\
\hline Sex (female/male) & $8 / 13$ \\
Median age (range) & $64(36-75)$ years \\
Primary tumour site & \\
$\quad$ Colon & 8 \\
Rectum & 13 \\
Histopathological type of primary site & \\
Well-differentiated adenocarcinoma & 5 \\
Moderately differentiated adenocarcinoma & 14 \\
Mucinous adenocarcinoma & 2 \\
Stage before initial operation & \\
III & 12 \\
IV (synchronous metastases) & 9
\end{tabular}

Tumour site characteristics

\begin{tabular}{lr}
\hline Metastases & 18 \\
Pre-FOLFOX & 12 \\
Synchronous & 6 \\
Metachronous & 24 \\
Post-FOLFOX & \\
Sites of metastases & \\
Pre-FOLFOX & 11 \\
Liver & 5 \\
Lung & 1 \\
Local recurrence & 1 \\
Subcutaneous & \\
Post-FOLFOX & 6 \\
Liver & 14 \\
Lung & 3 \\
Local recurrence & 1 \\
Lymph node & \\
\hline
\end{tabular}

liver (11 lesions), lung (5 lesions), as a local recurrence (1 lesion) and as a subcutaneous recurrence (1 lesion). Meanwhile, 24 metastatic lesions in the 21 patients were detected during or after FOLFOX therapy. These lesions were regarded as 'post-FOLFOX' metastatic lesions. The post-FOLFOX metastases were found in the liver, lung, as a local recurrence and lymph node in $6,14,3$ and 1 patients, respectively.

The median number of FOLFOX therapy cycles administered was 9 (3-12 cycles). Five patients experienced relapse during FOLFOX therapy (case 1, 2, 3, 7 and 12), whereas the remaining 16 patients experienced relapse after the end of FOLFOX therapy. The median disease-free survival, calculated from the time of the last operation until post-FOLFOX recurrence, was 409 days (97-1077). The median period from the start of FOLFOX therapy until recurrence was 373 days (35-1029). Relapses developed within 180 days after the end of FOLFOX therapy in 10 of the 21 patients (Table 2 ).

\section{Mutational status of KRAS and other genes}

The mutational statuses of KRAS and other genes in primary and metastatic lesions are shown in Table 3. Mutations in KRAS codons 12 and 13 were detected in 13 of the 21 primary colorectal tumours. Among the remaining eight tumours with wild-type KRAS codons 12 and 13, two tumours exhibited KRAS codon 146 mutations (A146V and A146T) and one tumour exhibited NRAS codon 61 mutation $(\mathrm{Q} 61 \mathrm{H})$. Two tumours exhibited mutations in PIK3CA codon 542 (E542K), one tumour exhibited a KRAS G12S mutation and one tumour had no mutations in any of the genes examined. No apparent mutations of KRAS codon $61, N R A S$ codon 
Table 2 FOLFOX treatment, metastasis status and tumour recurrence sites

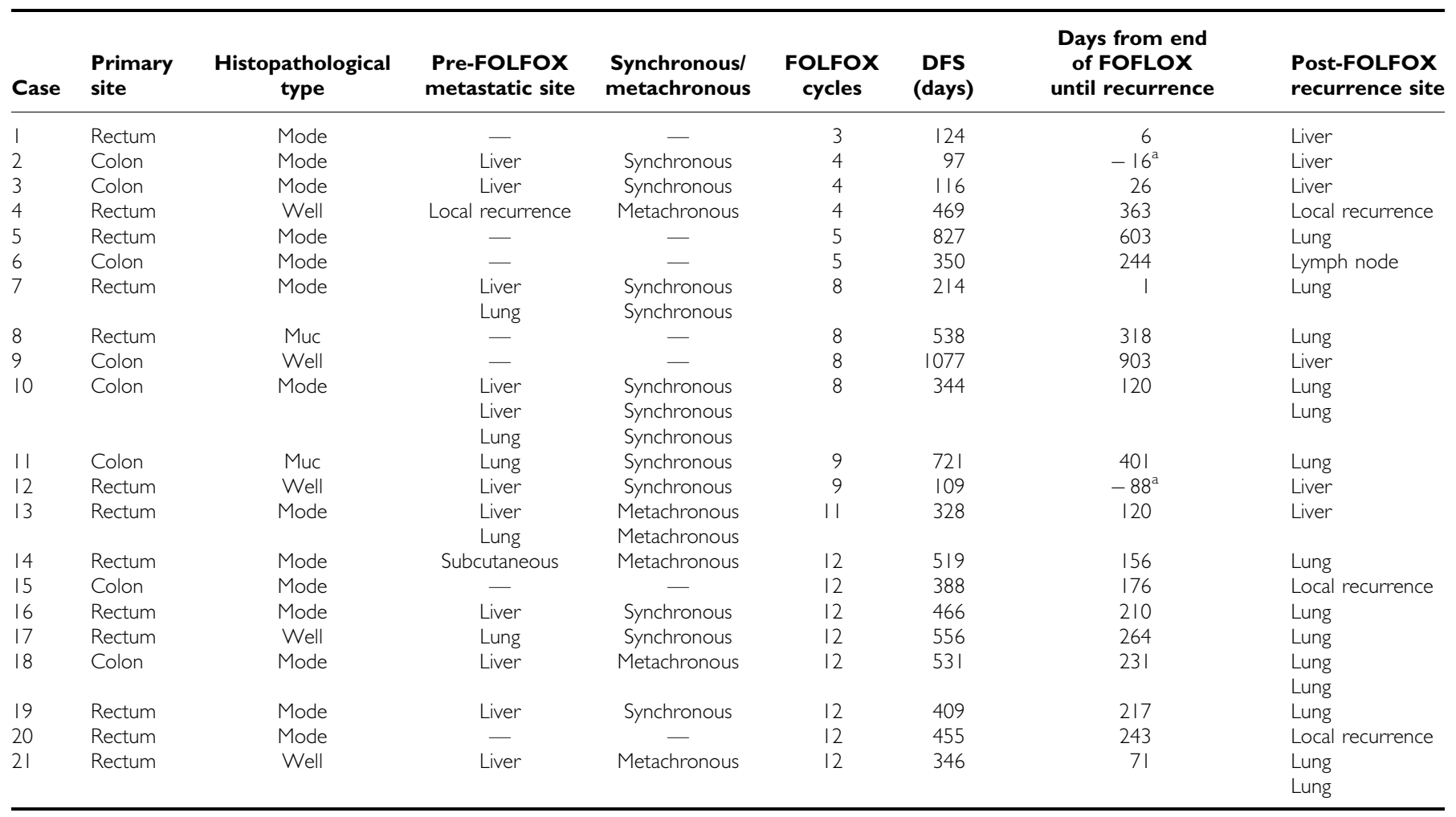

Abbreviations: DFS = disease-free survival; mode = moderately differentiated adenocarcinoma; muc = mucinous adenocarcinoma; well = well-differentiated adenocarcinoma

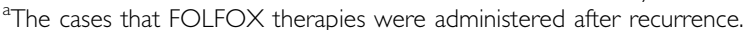

Table 3 Mutational status of KRAS and other genes

\begin{tabular}{|c|c|c|c|c|c|c|}
\hline Case & $\begin{array}{l}\text { Primary } \\
\text { site }\end{array}$ & $\begin{array}{c}\text { Mutation } \\
\text { status }\end{array}$ & $\begin{array}{c}\text { Pre-FOLFOX } \\
\text { metastatic site }\end{array}$ & $\begin{array}{c}\text { Mutation } \\
\text { status }\end{array}$ & $\begin{array}{l}\text { Post-FOLFOX } \\
\text { recurrence site }\end{array}$ & $\begin{array}{c}\text { Mutation } \\
\text { status }\end{array}$ \\
\hline I & Rectum & KRAS GI2D & - & - & Liver & KRAS GI2D \\
\hline 2 & Colon & KRAS GI2D & Liver & KRAS GI2D & Liver & KRAS GI2D \\
\hline 3 & Colon & KRAS GI2D & Liver & KRAS GI2D & Liver & KRAS GI2D \\
\hline 4 & Rectum & KRAS GI2R & Local recurrence & KRAS GI2R & Local recurrence & KRAS GI2R \\
\hline 5 & Rectum & KRAS GI2D & - & - & Lung & KRAS GI2D \\
\hline 6 & Colon & WT & - & - & LN & WT \\
\hline \multirow[t]{2}{*}{7} & Rectum & KRAS GI2S & Liver & KRAS GI2S & Lung & KRAS GI2S \\
\hline & & & Lung & KRAS GI2S & & \\
\hline 8 & Rectum & WT & - & - & Lung & WT \\
\hline 9 & Colon & WT & - & - & Liver & WT \\
\hline \multirow[t]{3}{*}{10} & Colon & KRAS GI2A & Liver & KRAS GI2A & Lung & KRAS GI2A \\
\hline & & & Liver & KRAS GI2A & Lung & KRAS GI2A \\
\hline & & & Lung & WT & & \\
\hline | | & Colon & KRAS GI3D & Lung & KRAS GI3D & Lung & KRAS GI3D \\
\hline 12 & Rectum & KRAS AI46V & Liver & KRAS AI46V & Liver & KRAS AI46V \\
\hline \multirow[t]{2}{*}{13} & Rectum & KRAS GI2V & Liver & KRAS GI2V & Liver & KRAS GI2V \\
\hline & & & Lung & KRAS GI2V & & \\
\hline 14 & Rectum & KRAS GI2D & Subcutaneous & KRAS GI2D & Lung & KRAS GI2D \\
\hline 15 & Colon & WT & - & - & Local recurrence & WT \\
\hline 16 & Rectum & KRAS GI2S, PIK3CA E542K & Liver & KRAS GI2S, PIK3CA E542K & Lung & KRAS GI2S, PIK3CA E542K \\
\hline 17 & Rectum & KRAS GI2D & Lung & KRAS GI2D & Lung & KRAS GI2D \\
\hline \multirow[t]{2}{*}{18} & Colon & KRAS GI2D & Liver & KRAS GI2D & Lung & KRAS GI2D \\
\hline & & & & & Lung & KRAS GI2D \\
\hline 19 & Rectum & NRAS Q6IH & Liver & NRAS Q6IH & Lung & NRAS Q6IH \\
\hline 20 & Rectum & PIK3CA E542K & - & - & Local recurrence & PIK3CA E542K \\
\hline \multirow[t]{2}{*}{21} & Rectum & KRAS AI46V & Liver & KRAS AI46V & Lung & KRAS AI46V \\
\hline & & & & & Lung & KRAS AI46V \\
\hline
\end{tabular}

Abbreviations: $\mathrm{LN}=$ lymph node; $\mathrm{WT}=$ wild-type. 
12 or $13, B R A F$ codon 600 , or PIK3CA codon 1047 were detected in any sample in this study.

The degree of concordance of the gene mutations in primary and pre-FOLFOX metastatic lesions was examined. In case 10 , a $K R A S$ G12A mutation was detected in the primary lesion, whereas the metastatic lesion in the lung had wild-type KRAS. Although the histological features of the lung lesion were consistent with metastatic adenocarcinoma of the colon, no mutations in the metastatic lesion were detected, even after repeated high-sensitivity examinations. The remaining 17 metastatic lesions in 14 patients, including 2 liver metastatic lesions in case 10 , showed the same mutational statuses as the primary tumours for all of the genes examined.

Then, the mutational statuses of the post-FOLFOX metastatic lesions were examined. The mutational statuses of all genes examined were identical in the 21 primary tumours and the corresponding 24 post-FOLFOX metastatic lesions, regardless of the sites involved, duration of FOLFOX treatment or disease-free survival period.

\section{DISCUSSION}

Previous studies have reported a high concordance rate of the KRAS mutations in primary and metastatic tumours (Oudejans et al, 1991; Losi et al, 1992; Suchy et al, 1992; Zauber et al, 2003; Weber et al, 2007; Etienne-Grimaldi et al, 2008; Santini et al, 2008; Garm Spindler et al, 2009; Loupakis et al, 2009; Perrone et al, 2009; Baldus et al, 2010; Italiano et al, 2010; Knijn et al, 2011). However, in patients receiving long-term chemotherapy, the effects of genotoxic chemotherapies, such as oxaliplatin, have not been well investigated.

In this study, we examined 21 patients with metastatic colorectal cancer who received adjuvant FOLFOX therapy. The recurrent tumours in three patients who showed relapse within 4 months after the primary surgery or during the first 3 or 4 cycles of adjuvant FOLFOX therapy (cases 1-3) were regarded as synchronous metastases arising from micrometastases that likely existed prior to the start of the adjuvant chemotherapy. The remaining 18 patients who developed relapses more than 8 months from the end of adjuvant FOLFOX therapy or after more than 6 cycles of adjuvant FOLFOX therapy were regarded as having metachronous

\section{REFERENCES}

Allegra CJ, Yothers G, O'Connell MJ, Sharif S, Colangelo LH, Lopa SH, Petrelli NJ, Goldberg RM, Atkins JN, Seay TE, Fehrenbacher L, O'Reilly S, Chu L, Azar CA, Wolmark N (2009) Initial safety report of NSABP C-08: a randomized phase III study of modified FOLFOX6 with or without bevacizumab for the adjuvant treatment of patients with stage II or III colon cancer. J Clin Oncol 27: 3385-3390

Amado RG, Wolf M, Peeters M, Van Cutsem E, Siena S, Freeman DJ, Juan T, Sikorski R, Suggs S, Radinsky R, Patterson SD, Chang DD (2008) Wild-type KRAS is required for panitumumab efficacy in patients with metastatic colorectal cancer. J Clin Oncol 26: 1626-1634

Andre T, Boni C, Mounedji-Boudiaf L, Navarro M, Tabernero J, Hickish T, Topham C, Zaninelli M, Clingan P, Bridgewater J, Tabah-Fisch I, de Gramont A (2004) Oxaliplatin, fluorouracil, and leucovorin as adjuvant treatment for colon cancer. $N$ Engl J Med 350: 2343-2351

Andreyev HJ, Norman AR, Cunningham D, Oates JR, Clarke PA (1998) Kirsten ras mutations in patients with colorectal cancer: the multicenter 'RASCAL' study. I Natl Cancer Inst 90: 675-684

Baldus SE, Schaefer KL, Engers R, Hartleb D, Stoecklein NH, Gabbert HE (2010) Prevalence and heterogeneity of KRAS, BRAF, and PIK3CA mutations in primary colorectal adenocarcinomas and their corresponding metastases. Clin Cancer Res 16: 790-799

Bando H, Yoshino T, Tsuchihara K, Ogasawara N, Fuse N, Kojima T, Tahara M, Kojima M, Kaneko K, Doi T, Ochiai A, Esumi H, Ohtsu A (2011) KRAS mutations detected by the amplification refractory metastatic tumours that had developed after exposure to oxaliplatin. Among these cases, tumour relapse occurred within 180 days after FOLFOX therapy in 7 patients and more than 180 days after FOLFOX therapy in the remaining 11 patients. Regardless of the treatment duration, 8 of the primary tumours with wild-type KRAS codons 12 and 13 did not acquire KRAS mutations. The remaining tumours with KRAS mutations also did not show additional mutations after FOLFOX therapy. Furthermore, none of the other genes that might potentially affect the efficacy of anti-EGFR antibody therapy were altered.

$K R A S, N R A S$ and BRAF mutations are all regarded as strong driver mutations that induce cell proliferation. These mutations might be acquired in the early stages of carcinogenesis and have generally been reported as mutually exclusive (Andreyev et al, 1998). Consistent with this observation, the KRAS and NRAS mutations in this study were found to be mutually exclusive. In the rest of the tumours, other unidentified driver mutations or amplifications may have activated the signalling pathways promoting cell proliferation. Considering the exclusive nature of the tested mutations, the acquisition of additional driver mutations may not be advantageous to these tumour cells for clonal selection. This could be one explanation for why the mutational statuses of KRAS and other genes were not altered during the development of metastatic tumours.

Our findings suggest that both the primary tumours and metastatic tumours arising during or after FOLFOX therapy could be valid sources of DNA for KRAS testing prior to treatment with anti-EGFR antibodies, although the number of cases in this study was limited. This finding should be further confirmed in a larger number of cases. Though collecting surgically resected metastatic tumour tissues is often difficult, circulating tumour cells may be a useful alternative DNA source for highly reliable and sensitive mutation detection systems such as the ARMS/Scorpion method for further analyses.

\section{ACKNOWLEDGEMENTS}

The study was supported by the National Cancer Center Research and Development Fund, 23-A-2, awarded to KT and TY. mutation system-Scorpion assays strongly correlate with therapeutic effect of cetuximab. Br J Cancer 105: 403-406

Benvenuti S, Sartore-Bianchi A, Di Nicolantonio F, Zanon C, Moroni M, Veronese S, Siena S, Bardelli A (2007) Oncogenic activation of the RAS/RAF signaling pathway impairs the response of metastatic colorectal cancers to anti-epidermal growth factor receptor antibody therapies. Cancer Res 67: 2643-2648

De Roock W, Claes B, Bernasconi D, De Schutter J, Biesmans B, Fountzilas G, Kalogeras KT, Kotoula V, Papamichael D, Laurent-Puig P, Penault-Llorca F, Rougier P, Vincenzi B, Santini D, Tonini G, Cappuzzo F, Frattini M, Molinari F, Saletti P, De Dosso S, Martini M, Bardelli A, Siena S, Sartore-Bianchi A, Tabernero J, Macarulla T, Di Fiore F, Gangloff AO, Ciardiello F, Pfeiffer P, Qvortrup C, Hansen TP, Van Cutsem E, Piessevaux H, Lambrechts D, Delorenzi M, Tejpar S (2010) Effects of KRAS, BRAF, NRAS, and PIK3CA mutations on the efficacy of cetuximab plus chemotherapy in chemotherapy-refractory metastatic colorectal cancer: a retrospective consortium analysis. Lancet Oncol 11: 753-762

De Roock W, Piessevaux H, De Schutter J, Janssens M, De Hertogh G, Personeni N, Biesmans B, Van Laethem JL, Peeters M, Humblet Y, Van Cutsem E, Tejpar S (2008) KRAS wild-type state predicts survival and is associated to early radiological response in metastatic colorectal cancer treated with cetuximab. Ann Oncol 19: 508-515

Di Fiore F, Blanchard F, Charbonnier F, Le Pessot F, Lamy A, Galais MP, Bastit L, Killian A, Sesboue R, Tuech JJ, Queuniet AM, Paillot B, Sabourin JC, Michot F, Michel P, Frebourg T (2007) Clinical relevance of KRAS 
mutation detection in metastatic colorectal cancer treated by Cetuximab plus chemotherapy. Br J Cancer 96: 1166-1169

Etienne-Grimaldi MC, Formento JL, Francoual M, Francois E, Formento P, Renee N, Laurent-Puig P, Chazal M, Benchimol D, Delpero JR, Letoublon C, Pezet D, Seitz JF, Milano G (2008) K-Ras mutations and treatment outcome in colorectal cancer patients receiving exclusive fluoropyrimidine therapy. Clin Cancer Res 14: 4830-4835

Frattini M, Saletti P, Romagnani E, Martin V, Molinari F, Ghisletta M, Camponovo A, Etienne LL, Cavalli F, Mazzucchelli L (2007) PTEN loss of expression predicts cetuximab efficacy in metastatic colorectal cancer patients. Br J Cancer 97: 1139-1145

Freeman DJ, Juan T, Reiner M, Hecht JR, Meropol NJ, Berlin J, Mitchell E, Sarosi I, Radinsky R, Amado RG (2008) Association of K-ras mutational status and clinical outcomes in patients with metastatic colorectal cancer receiving panitumumab alone. Clin Colorectal Cancer 7: 184-190

Garm Spindler KL, Pallisgaard N, Rasmussen AA, Lindebjerg J, Andersen RF, Cruger D, Jakobsen A (2009) The importance of KRAS mutations and EGF61A $>$ G polymorphism to the effect of cetuximab and irinotecan in metastatic colorectal cancer. Ann Oncol 20: 879-884

Hah SS, Sumbad RA, de Vere White RW, Turteltaub KW, Henderson PT (2007) Characterization of oxaliplatin-DNA adduct formation in DNA and differentiation of cancer cell drug sensitivity at microdose concentrations. Chem Res Toxicol 20: 1745-1751

Italiano A, Hostein I, Soubeyran I, Fabas T, Benchimol D, Evrard S, Gugenheim J, Becouarn Y, Brunet R, Fonck M, Francois E, Saint-Paul MC, Pedeutour F (2010) KRAS and BRAF mutational status in primary colorectal tumors and related metastatic sites: biological and clinical implications. Ann Surg Oncol 17: 1429-1434

Karapetis CS, Khambata-Ford S, Jonker DJ, O'Callaghan CJ, Tu D, Tebbutt NC, Simes RJ, Chalchal H, Shapiro JD, Robitaille S, Price TJ, Shepherd L, Au HJ, Langer C, Moore MJ, Zalcberg JR (2008) K-ras mutations and benefit from cetuximab in advanced colorectal cancer. N Engl J Med 359: 1757-1765

Khambata-Ford S, Garrett CR, Meropol NJ, Basik M, Harbison CT, Wu S, Wong TW, Huang X, Takimoto CH, Godwin AK, Tan BR, Krishnamurthi SS, Burris III HA, Poplin EA, Hidalgo M, Baselga J, Clark EA, Mauro DJ (2007) Expression of epiregulin and amphiregulin and K-ras mutation status predict disease control in metastatic colorectal cancer patients treated with cetuximab. J Clin Oncol 25: 3230-3237

Knijn N, Mekenkamp LJ, Klomp M, Vink-Borger ME, Tol J, Teerenstra S, Meijer JW, Tebar M, Riemersma S, van Krieken JH, Punt CJ, Nagtegaal ID (2011) KRAS mutation analysis: a comparison between primary tumours and matched liver metastases in 305 colorectal cancer patients. Br J Cancer 104(6): 1020-1026

Lievre A, Bachet JB, Boige V, Cayre A, Le Corre D, Buc E, Ychou M, Bouche O, Landi B, Louvet C, Andre T, Bibeau F, Diebold MD, Rougier P, Ducreux M, Tomasic G, Emile JF, Penault-Llorca F, Laurent-Puig P (2008) KRAS mutations as an independent prognostic factor in patients with advanced colorectal cancer treated with cetuximab. J Clin Oncol 26: 374-379

Lievre A, Bachet JB, Le Corre D, Boige V, Landi B, Emile JF, Cote JF, Tomasic G, Penna C, Ducreux M, Rougier P, Penault-Llorca F, Laurent-Puig P (2006) KRAS mutation status is predictive of response to cetuximab therapy in colorectal cancer. Cancer Res 66: 3992-3995

Losi L, Benhattar J, Costa J (1992) Stability of K-ras mutations throughout the natural history of human colorectal cancer. Eur J Cancer 28A: $1115-1120$

Loupakis F, Pollina L, Stasi I, Ruzzo A, Scartozzi M, Santini D, Masi G, Graziano F, Cremolini C, Rulli E, Canestrari E, Funel N, Schiavon G,
Petrini I, Magnani M, Tonini G, Campani D, Floriani I, Cascinu S, Falcone A (2009) PTEN expression and KRAS mutations on primary tumors and metastases in the prediction of benefit from cetuximab plus irinotecan for patients with metastatic colorectal cancer. J Clin Oncol 27: 2622-2629

Oliveira C, Westra JL, Arango D, Ollikainen M, Domingo E, Ferreira A, Velho S, Niessen R, Lagerstedt K, Alhopuro P, Laiho P, Veiga I, Teixeira MR, Ligtenberg M, Kleibeuker JH, Sijmons RH, Plukker JT, Imai K, Lage P, Hamelin R, Albuquerque C, Schwartz Jr S, Lindblom A, Peltomaki P, Yamamoto H, Aaltonen LA, Seruca R, Hofstra RM (2004) Distinct patterns of KRAS mutations in colorectal carcinomas according to germline mismatch repair defects and hMLH1 methylation status. Hum Mol Genet 13: 2303-2311

Oudejans JJ, Slebos RJ, Zoetmulder FA, Mooi WJ, Rodenhuis S (1991) Differential activation of ras genes by point mutation in human colon cancer with metastases to either lung or liver. Int J Cancer 49: 875-879

Perrone F, Lampis A, Orsenigo M, Di Bartolomeo M, Gevorgyan A, Losa M, Frattini M, Riva C, Andreola S, Bajetta E, Bertario L, Leo E, Pierotti MA, Pilotti S (2009) PI3KCA/PTEN deregulation contributes to impaired responses to cetuximab in metastatic colorectal cancer patients. Ann Oncol 20: 84-90

Santini D, Loupakis F, Vincenzi B, Floriani I, Stasi I, Canestrari E, Rulli E, Maltese PE, Andreoni F, Masi G, Graziano F, Baldi GG, Salvatore L, Russo A, Perrone G, Tommasino MR, Magnani M, Falcone A, Tonini G, Ruzzo A (2008) High concordance of KRAS status between primary colorectal tumors and related metastatic sites: implications for clinical practice. Oncologist 13: 1270-1275

Sharma S, Gong P, Temple B, Bhattacharyya D, Dokholyan NV, Chaney SG (2007) Molecular dynamic simulations of cisplatin- and oxaliplatin$\mathrm{d}(\mathrm{GG})$ intrastand cross-links reveal differences in their conformational dynamics. J Mol Biol 373: 1123-1140

Silva MJ, Costa P, Dias A, Valente M, Louro H, Boavida MG (2005) Comparative analysis of the mutagenic activity of oxaliplatin and cisplatin in the Hprt gene of $\mathrm{CHO}$ cells. Environ Mol Mutagen 46: 104-115

Suchy B, Zietz C, Rabes HM (1992) K-ras point mutations in human colorectal carcinomas: relation to aneuploidy and metastasis. Int J Cancer 52: 30-33

Weber JC, Meyer N, Pencreach E, Schneider A, Guerin E, Neuville A, Stemmer C, Brigand C, Bachellier P, Rohr S, Kedinger M, Meyer C, Guenot D, Oudet P, Jaeck D, Gaub MP (2007) Allelotyping analyses of synchronous primary and metastasis CIN colon cancers identified different subtypes. Int J Cancer 120: 524-532

Woynarowski JM, Faivre S, Herzig MC, Arnett B, Chapman WG, Trevino AV, Raymond E, Chaney SG, Vaisman A, Varchenko M, Juniewicz PE (2000) Oxaliplatin-induced damage of cellular DNA. Mol Pharmacol 58: 920-927

Zauber P, Sabbath-Solitare M, Marotta SP, Bishop DT (2003) Molecular changes in the Ki-ras and APC genes in primary colorectal carcinoma and synchronous metastases compared with the findings in accompanying adenomas. Mol Pathol 56: 137-140

cC)(D) This work is licensed under the Creative Commons BY NC SA Attribution-NonCommercial-Share Alike 3.0 Unported License. To view a copy of this license, visit http:// creativecommons.org/licenses/by-nc-sa/3.0/ 